\title{
IMPACTOS DO PROGRAMA BOLSA FAMÍLIA FEDERAL SOBRE O TRABALHO INFANTIL E A FREQUÊNCIA ESCOLAR*
}

\author{
Maria Cristina Cacciamali*
}

Fábio Tatei ${ }^{* * *}$

\section{Natália Ferreira Batista ${ }^{* * *}$}

RESUMO Este trabalho analisa o impacto do Programa Bolsa Família sobre a incidência de trabalho infantil e a frequência escolar das crianças de famílias pobres no Brasil em 2004, segundo a situação censitária e regional. Para o cálculo dos testes estatísticos, utilizamos um modelo probit bivariado, que estima conjuntamente as opções trabalhar e estudar dos jovens. Os resultados corroboram a eficiência do Programa Bolsa Família em elevar a frequência escolar das crianças; contudo, o Programa apresenta efeitos perversos sobre a incidência de trabalho infantil, elevando a probabilidade de sua ocorrência. Ademais, crianças de famílias pobres situadas em áreas rurais apresentam piores condições em relação àquelas de áreas urbanas, demandando ações específicas a seu favor.

* Artigo enviado em 16 de outubro de 2008 e aprovado em 16 de abril de 2010.

** Mestre, doutora e livre-docente pela Universidade de São Paulo. Professora titular da Faculdade de Economia, Administração e Contabilidade (FEA) e do Programa de Pós-graduação em Integração em América Latina (Prolam) da Universidade de São Paulo (USP). Pesquisadora do Conselho Nacional de Pesquisa e Tecnologia e perita da Organização Internacional do Trabalho para o Seguimento dos Direitos Fundamentais no Trabalho. Coordenadora do Núcleo de Estudos e Pesquisas de Política Internacional, Estudos Internacionais \& Políticas Comparadas, Nespi - USP/CNPq, e-mail: cciamali@uol.com.br

*** Economista pela Faculdade de Economia, Administração e Contabilidade da Universidade de São Paulo e mestrando do Programa de Pós-Graduação Interunidades em Ciências da Integração da América Latina (Prolam/USP). Atualmente é assistente de pesquisa bolsista do CNPq e membro do Nespi - USP/CNPq, e-mail: ftatei@gmail.com

**** Doutora pela Universidade de São Paulo. Atualmente é professora da Faculdade de Economia, Administração e Contabilidade da Universidade de São Paulo, campus de Ribeirão Preto, e membro do Nespi - USP/CNPq, e-mail: nbatista@fearp.usp.br 
Palavras-chave: Programa Bolsa Família; trabalho infantil; frequência escolar; programas de transferência de renda com condicionalidades

Código JEL: J13; J18; J22

\section{IMPACTS OF THE BOLSA FAMÍLIA PROGRAM ON \\ CHILD LABOR AND SCHOOL ATTENDANCE}

ABSTRACT This paper analyses the impacts of the Bolsa Familia Program on the occurrence of child labor and school attendance of children from poor families in Brazil in 2004, according to census and regional areas. A bivariate probit model was used to estimate the statistical tests. The results corroborate the efficiency of the Bolsa Familia to increase the school attendance of children, however, the Program increases the likelihood of occurrence of child labor. Moreover, children of poor households in rural areas have worse conditions than those of urban areas, demanding specific actions to them.

Key words: Bolsa Família Program; child labor; school attendance; conditional cash transfers programs 


\section{INTRODUÇÃO}

O objetivo deste trabalho é analisar o impacto do programa de transferência de renda do governo federal Bolsa Família sobre a incidência de trabalho infantil e a frequência escolar das crianças, duas opções que se encontram intrinsecamente correlacionadas no caso dos jovens. ${ }^{1} \mathrm{~A}$ justificativa desta proposta relaciona-se à constatação de que, apesar do aumento dos gastos sociais no Brasil e de sua efetividade, a curto prazo, no combate à pobreza crônica, não há evidências de redução significativa do trabalho infantil entre as crianças das famílias pobres, o que sugeriria a necessidade de aprimoramento desses programas.

A redução da pobreza e a sua erradicação são temas habituais em debates sobre o desenvolvimento humano, ao mesmo tempo em que a própria conceituação de pobreza é objeto de discussão. ${ }^{2}$ É reconhecido que reduções de pobreza apenas podem ser obtidas mediante a elevação da renda dos mais pobres, o que, inerentemente, demanda investimentos para a elevação do estoque de seu capital humano. Entretanto, a população de baixa renda se vê obrigada a ingressar no mercado de trabalho precocemente, para complementar a renda familiar ou garantir sua própria sobrevivência, não raro alocando o tempo em detrimento dos estudos e, consequentemente, deteriorando as suas oportunidades futuras de auferir renda mais elevada. Ademais, essa parcela da população ocupa postos de trabalho de menor qualificação, recebendo salários baixos, perpetuando, assim, a sua condição de pobreza.

Destarte, o combate à pobreza pede ações específicas capazes de romper essa armadilha entre gerações, dentre as quais destacamos o papel dos programas de transferências focalizadas de renda. Voltadas para as famílias carentes, o cerne dessas políticas é eliminar e/ou amenizar, a curto prazo, as dificuldades acarretadas pela condição de pobreza. Ao promover a transferência direta de renda com condicionalidades - frequência escolar, atendimento médico, entre as condições mais frequentemente utilizadas —, os programas enfrentam dois aspectos que caracterizam a reprodução do ciclo da pobreza entre gerações: garantem nível mínimo de renda de subsistência para as famílias pobres e resguardam a obtenção de capital humano de seus beneficiários. 
Adicionalmente, a importância da redução da pobreza, além dos aspectos morais, prende-se ao fato de que estudos revelam que, em nível macro, a pobreza é um dos fatores que explicam o baixo crescimento econômico dos países da América Latina, de modo que a sua eliminação ou mesmo simples redução apresentaria efeitos positivos para o crescimento e desenvolvimento da nação. ${ }^{3}$

Sob a ótica da teoria econômica, os programas de transferência de renda provocam um efeito renda puro na tomada de decisão da família sobre uso do tempo das crianças entre trabalho, educação e lazer. Considerando que estes últimos podem ser considerados como bens de luxo, a teoria econômica afirma que o seu consumo aumenta mais que proporcionalmente com a elevação da renda familiar. Ou seja, à medida que os ganhos da família se elevam, os seus membros poderão alocar maior tempo para o lazer ou estudo, sem prejuízo ao mínimo necessário para sua subsistência. Essas considerações implicariam diminuição do trabalho infantil das famílias pobres.

Assim, a análise dessas questões será efetuada em quatro seções, além desta introdução e das considerações finais. A primeira descreve a evolução e os desenhos dos principais programas de transferência de renda no Brasil. A segunda seção consiste na revisão ampliada e aprofundada da bibliografia sobre o tema, elaborada a partir de três eixos: determinantes da ocorrência do trabalho infantil nas famílias mais pobres; determinantes da alocação do tempo das crianças entre trabalho, escola e lazer; e resultados da avaliação dos programas de transferência de renda, com condicionalidade e sem condicionalidade, implementados no Brasil e no exterior. Em seguida, a terceira seção apresenta a metodologia e a base de dados utilizadas neste trabalho, enquanto os resultados são apresentados na quarta seção. Por fim, tecemos as considerações finais.

\section{O EMPREGO CRESCENTE DOS PROGRAMAS DE TRANSFERÊNCIA DE RENDA NO ÂMBITO DA POLÍTICA SOCIAL}

Desde o final do século passado, em praticamente todos os países do mundo, os Programas de Proteção Social ${ }^{4}$ tornam-se mais atraentes politicamente do que a ampliação nos Sistemas de Seguridade Social ${ }^{5}$ para combater as desigualdades de renda e a pobreza, por dois motivos. O primeiro é o 
aumento no número de excluídos do Sistema de Seguridade Social, como o aumento no número de desempregados de longa duração que perdem o benefício do seguro-desemprego, ou o maior número de famílias, crianças e jovens pobres, especialmente nos países em desenvolvimento, além de, muitas vezes, o aumento da desigualdade na distribuição de renda. O segundo é o reconhecimento por parte da comunidade científica, técnica e política de que, embora o crescimento econômico sustentável, a estabilidade macroeconômica e a boa governança sejam fundamentais para reduzir a pobreza, são fatores insuficientes. A pobreza é identificada como um fenômeno multidimensional, que necessita de um conjunto de programas microeconômicos integrados para a sua superação, além de contar com condições macroeconômicas favoráveis.

Os programas de transferência de renda se caracterizam por um conjunto de singularidades perante os programas tradicionais dos sistemas de seguridade social, mostrando-se adequados para fins de desenvolver programas de promoção humana. Em primeiro lugar, os programas de transferência de renda outorgam maior controle aos pobres sobre as suas tomadas de decisão por meio de mecanismos de mercado, uma vez que a ação pública ocorre pelo lado da demanda, provendo suporte direto para os beneficiários, ao invés de acontecer pelo lado da oferta de serviços sociais. Em segundo lugar, os programas priorizam a acumulação de capital humano, via educação e saúde, especialmente para crianças e jovens, com o objetivo de romper ciclo intergeracional da pobreza. Esse tipo de intervenção, em terceiro lugar, apresenta vantagens consideráveis, como baixos custos de transação; reorientação de desequilíbrios de informação, pois as famílias são mais bem informadas sobre si mesmas do que o governo; melhor focalização do que programas de cunho universal; e maior flexibilidade para alterações de beneficiários e benefícios. Em quarto lugar, a característica de flexibilidade desse tipo de programa recai sobre a adequação continuada entre os objetivos políticos e as restrições do orçamento público, na medida em que a transferência de renda não está instituída como um direito social, podendo ser suspensa a qualquer momento. Em quinto lugar, o programa se constitui em uma rede de seguridade em momentos de crise econômica, por exemplo, desemprego em massa devido a reestruturação produtiva ou acidentes climáticos, apresentando maior potencial de alcançar impactos significativos 
no bem-estar dos beneficiários, devido aos seus efeitos multiplicadores locais sobre as comunidades.

Nesses termos, nos últimos anos e, em especial, na América Latina, os programas de transferência de renda constituem-se em uma política efetiva de combate à pobreza, ao focar na população mais carente e apresentar condicionalidades que beneficiam a proteção e o acúmulo de capital humano, por meio da obrigatoriedade de presença no sistema escolar e atendimento médico disponível. A eficiência dos instrumentos de Proteção Social é observada em muitos estudos empíricos, mostrando que os programas voltados à educação e saúde obtiveram sucesso aumentando a frequência à escola e diminuindo as taxas de mortalidade infantil, morte de mulheres no parto e índices de desnutrição de crianças. ${ }^{6}$ Os mesmos resultados são observados em programas de transferência de renda com condicionalidade que, em geral, visam a aumentar a frequência à escola e o aproveitamento escolar, além de melhorar comportamentos de prevenção à saúde. Na América Latina, essa modalidade de programa se expande na última década, atingindo, em 2006, 14 milhões de famílias, em especial no Brasil, México e Argentina. ${ }^{7}$

No Brasil, a partir de 1994, iniciou-se um programa de transferência de renda condicionada à frequência escolar. ${ }^{8}$ Criado pelo governador Cristóvam Buarque no Distrito Federal, o Programa Bolsa Escola distribuía benefício mensal no valor de um salário mínimo para as famílias que mantivessem suas crianças no sistema escolar. Em 1998, o programa beneficiou 26 mil famílias, uma cobertura aproximada de $80 \%$ do público-alvo potencial de famílias com renda por pessoa inferior a meio salário mínimo R \$ 75,00, na época. Graças ao seu sucesso e reduzido custo, o Bolsa Escola passou a ser aplicado em diversos municípios do país; no entanto, a ineficácia na implantação, execução e monitoramento do programa fez com que os objetivos propostos não fossem plenamente atingidos. ${ }^{9}$

Em 2001, consolidando experiências municipais e objetivando o combate à evasão escolar e trabalho infantil entre as famílias carentes, o governo federal lançou o Programa Nacional de Renda Mínima vinculada à Educação - Bolsa Escola ou Programa Bolsa Escola Federal. ${ }^{10} \mathrm{O}$ programa passa a agregar as famílias com crianças de idade entre 6 e 15 anos, matriculadas em estabelecimentos de ensino que apresentassem frequência escolar de 
$85 \%$ ou mais. O limite de renda por pessoa da família foi definido pelo Poder Executivo em cada exercício, e o valor pago era de R\$15,00 por beneficiário, com até três beneficiários por família.

Posteriormente, em 2003, o Poder Executivo federal reuniu um conjunto de programas de transferência de renda (Bolsa Escola, Bolsa Alimentação, Auxílio-Gás, e Cartão-Alimentação) sob o Programa Bolsa Família (PBF). ${ }^{11}$ Beneficiando-se da existência do Cadastro Único (Cadúnico), ${ }^{12}$ atualmente o PBF é o maior programa de transferência de renda no Brasil, destinado às famílias que dispõem de baixos recursos, prevendo contrapartidas de acompanhamento da saúde e estado nutricional das gestantes e dos filhos, matrícula e $85 \%$ de frequência escolar de crianças na idade entre 7 e 15 anos, e a participação em programas de educação alimentar. Em outubro de 2008, o PBF transferiu às famílias pobres - renda familiar por pessoa de até $\mathrm{R} \$ 120,00$ - o valor de $\mathrm{R} \$ 20,00$ para cada criança entre 0 e 15 anos de idade, até o limite de três benefícios por família, além de um benefício variável no valor de $\mathrm{R} \$ 30,00$ para cada jovem de 16 e 17 anos que frequenta a escola — limitado a dois benefícios por família. ${ }^{13}$ Além desse benefício variável, as famílias extremamente pobres - renda por pessoa de até $\mathrm{R} \$ 60,00$ — têm direito ao recebimento de um benefício fixo, no valor de R $\$ 62,00$.

Paralelamente, em 1996, foi instituído o Programa de Erradicação do Trabalho Infantil (Peti), primeiro programa de transferência de renda em nível federal. Implantado inicialmente nas carvoarias do Mato Grosso do Sul, o programa compreende a realização de ações socioeducativas e de cidadania realizadas, em grande parte, por organizações do terceiro setor. O objetivo do Peti é retirar crianças e adolescentes entre 7 e 15 anos do trabalho perigoso, penoso, insalubre e degradante, além de sua manutenção na escola e na Jornada Ampliada. Com a Portaria GM/MDS nº 666, de 28 de dezembro de 2005, do Ministério do Desenvolvimento Social e Combate à Fome, o Peti passou a abranger apenas as famílias com renda por pessoa superior a $\mathrm{R} \$ 120,00,{ }^{14}$ e famílias com renda inferior ao piso deverão ser atendidas pelo Programa Bolsa Família. Ademais, o programa amplia a elegibilidade de crianças a serem atendidas, incluindo toda a população com idade inferior a 16 anos, em diversas situações de trabalho. ${ }^{15} \mathrm{O}$ valor do benefício mensal em 2008 era de $\mathrm{R} \$ 40,00$ por criança ocupada residente em áreas urbanas, ${ }^{16}$ e R \$25,00 por criança ocupada nas áreas rurais, sem limi- 
tes de inclusão de crianças/adolescentes por família se estiverem trabalhando. ${ }^{17}$ Em contrapartida, além da retirada do trabalho, as crianças beneficiadas devem apresentar frequência mínima de 85\% na escola e em Ações Socioeducativas e de Convivência (Jornada Ampliada). ${ }^{18}$

\section{RACIONALIZAÇÃO E ARGUMENTOS TEÓRICOS}

A literatura especializada internacional frequentemente registra a pobreza como principal causa para a persistência do fenômeno no mundo, ${ }^{19}$ pois a família faz uso do trabalho da criança apenas quando a sua renda não é suficiente para manter um nível mínimo de qualidade de vida. ${ }^{20}$ Contudo, diversos estudos destacam a complementaridade e importância de outros fatores na determinação de sua ocorrência.

No Brasil, dentre outros, Maria Cristina Cacciamali e Fábio Tatei (2008) apresentam evidências de que a probabilidade de incidência de trabalho infantil é maior entre as famílias chefiadas por trabalhadores por conta própria, principalmente aqueles do setor agrícola. ${ }^{21}$ Ademais, os autores apontam que a participação de jovens e crianças no mercado de trabalho está estreitamente relacionada aos níveis de educação dos pais, de modo que, quanto mais escolarizados, maior será a sua preferência pela escolarização mais elevada dos filhos. Por sua vez, Natália Nunes Ferreira Batista e Maria Cristina Cacciamali (2007) apontam que famílias migrantes recém-chegadas ao Estado de São Paulo também mostram maior probabilidade de trabalho infantil e de adolescentes, e, independentemente de sua condição de migração, mulheres sem cônjuges responsáveis por famílias também apresentam maior probabilidade de trabalho infantojuvenil. ${ }^{22}$ Avançando nessa direção, Cacciamali, Batista e Tatei utilizam um probit bivariado para analisar o efeito do status ocupacional dos pais sobre a incidência de trabalho infantil e frequência escolar das crianças no Brasil em 2005. ${ }^{23}$ Os resultados corroboram os estudos anteriores, indicando que a maior parte da diferença observada na probabilidade de ocorrência de trabalho infantil e na frequência escolar deve-se justamente às características intrínsecas da situação ocupacional por conta própria dos responsáveis da família. ${ }^{24}$

Por sua vez, a avaliação dos programas de transferência de renda apresenta resultados positivos, especialmente quando o seu desenho prevê condicionalidades, como veremos adiante. 
César Patricio Bouillon e Luis Tejerina (2006) resenham 51 trabalhos que tratam de 47 programas de proteção social na América Latina e Caribe. ${ }^{25}$ Todos os trabalhos foram selecionados por empregarem um processo de avaliação que utiliza o estimador diferença-em-diferenças, comparando, entre as famílias participantes e não participantes, as mudanças na variável objeto da intervenção antes e após a implementação dos programas. ${ }^{26}$ Dentre os principais resultados observados pelos autores, destacamse maior frequência das crianças à escola, maiores gastos familiares no consumo alimentar, redução da natalidade e mortalidade infantil, e diminuição do número de crianças ocupadas ou de horas dedicadas ao trabalho, no caso dos programas que preveem frequência diária integral da criança na escola. Igualmente, Sudhanshu Handa e Benjamin Davis (2006) analisam diversos estudos que abarcam programas de transferências de renda com condicionalidade executados na América Latina: Bolsa Escola/ Bolsa Família (Brasil), Familias en Acción (Colômbia), PRAF II (Honduras), PATH (Jamaica), Progresa/Oportunidades (México) e RPS (Nicarágua). ${ }^{27}$ Os autores observam que, em geral, os programas conseguem atingir suas metas básicas, como melhorar a frequência escolar e saúde das crianças nas famílias beneficiadas. ${ }^{28}$

Por sua vez, Suzanne Duryea e Andrew Morrison (2004) analisam os impactos do Superémonos - programa de transferência de renda condicional na Costa Rica - sobre a frequência e rendimento escolar das crianças e incidência de trabalho infantil. ${ }^{29}$ Para tanto, os autores utilizam três métodos empíricos: comparação simples de médias, regressão probit e propensity score matching. Os resultados obtidos indicam que o programa é eficaz em elevar o atendimento escolar das crianças de famílias beneficiadas, enquanto os impactos positivos sobre o desempenho escolar são menos significantes. ${ }^{30}$ Por outro lado, o estudo não encontra evidências de redução na ocupação das crianças de famílias beneficiadas. Apesar de o combate ao trabalho infantil não ser alvo do programa, os autores apontam evidências de que programas de transferência de renda, complementados por intervenções adicionais, reduzem significativamente o trabalho infantil. ${ }^{31}$

O mesmo argumento é sustentado por Fábio Veras Soares (2004), que reafirma a importância das condicionalidades nos programas de transferências de renda ao apontar estudos que indicam que o Programa Bolsa Escola 
aumenta a frequência escolar, mas não reduz o trabalho infantil, enquanto o Peti atinge esses dois objetivos. A diferença nos resultados se deve ao fato de o Peti oferecer atividades extracurriculares para manter as crianças ocupadas ao longo do dia, reforçando as evidências de que a ampliação da jornada escolar ou a introdução de atividades extraclasse são eficientes para reduzir a ocorrência de trabalho produtivo das crianças. ${ }^{32}$

Nesse sentido, Simon Schwartzman (2005) avalia os impactos de programas sociais voltados à educação, em particular o Programa Bolsa Escola, a partir de dados da Pesquisa Nacional por Amostra de Domicílios (PNAD) de $2003 .{ }^{33} \mathrm{O}$ autor contesta o critério de focalização desse programa, pois beneficia crianças que já estão na escola, principalmente estudantes do ensino fundamental, ao invés de atender a crianças e adolescentes que não participam do sistema escolar ou que estão em programas especiais de volta à escola. ${ }^{34}$ Ele ressalta, ainda, que não é possível afirmar que a maior frequência escolar possa estar relacionada à condicionalidade imposta pelo programa, uma vez que os jovens que não comparecem à escola não fazem parte do público-alvo do programa e das estatísticas. Por outro lado, o programa mostra focalização adequada de acordo com o critério de renda, sendo mais significativo para as famílias mais pobres, apesar do viés rural, uma vez que as famílias mais pobres se concentram em áreas urbanas. Schwartzman (2005) ainda apresenta os resultados da correlação entre a frequência escolar e o trabalho infantil, que, ao contrário do esperado, indicam que as crianças beneficiárias do programa trabalham mais. Segundo o autor, esse comportamento é justificável, pois as famílias beneficiadas são as mais pobres e, portanto, necessitam da renda proveniente do trabalho de suas crianças para se sustentarem. Desse modo, Schwartzman (2005) sustenta que as crianças não deixam de ir à escola porque trabalham, mas, sim, por problemas do próprio sistema escolar, como escolas não acessíveis e baixa qualidade do ensino.

Eliana Cardoso e André Portela de Souza (2004), por outro lado, analisam os impactos dos programas de transferência de renda sobre a frequência escolar e o trabalho infantil com base no método econométrico de emparelhamento baseado no escore de propensão (propensity matching score method) empregando os microdados do Censo brasileiro de $2000 .{ }^{35} \mathrm{O}$ estudo revela que os programas de transferência de renda não apresentam efei- 
tos significantes sobre a incidência de trabalho infantil, mas, sim, sobre a frequência escolar. Ou seja, os programas aumentam as chances de as crianças pobres estudarem, mas não reduzem as chances de estarem ocupadas. Isso se dá porque, provavelmente, ocorre apenas uma alteração no tempo alocado entre estudo e trabalho, considerando que os benefícios pagos pelos programas são insuficientes para incentivar o abandono da ocupação. Ademais, os resultados de Cardoso e Portela de Souza apontam que as transferências reduzem a proporção de crianças que só trabalham e aquelas que não estudam nem trabalham, e aumentam a proporção de crianças que apenas estudam e que estudam e trabalham. Contudo, não são encontradas evidências que condicionam diretamente o pagamento de benefícios à redução do trabalho infantil.

Na mesma linha de raciocínio, Andréa Rodrigues Ferro e Ana Lúcia Kassouf (2005) avaliam o impacto do Programa Bolsa Escola sobre o trabalho infantil. Para fazer essa análise, as autoras utilizam dois modelos econométricos empregando os dados da PNAD de 2001: um modelo probit ponderado, cuja variável dependente binária é a criança estar trabalhando ou não; e um modelo de mínimos quadrados ponderados, considerando as horas semanais trabalhadas como variável dependente. ${ }^{36}$ As autoras apontam que os programas de transferência de renda não estabelecem a contrapartida de as crianças não estarem trabalhando, mas como exigem a frequência escolar, isso por si só já reduz o tempo disponível para que elas se ocupem no mercado de trabalho. Ademais, o Programa Bolsa Escola atinge indiretamente essa questão, pois a renda oriunda do programa substituiria, de certo modo, a renda proveniente do trabalho. Desse modo, da mesma forma que Cardoso e Portela de Souza, Ferro e Kassouf concluem que o Programa Bolsa Escola é eficiente na redução da jornada de trabalho das crianças, em especial para aquelas de áreas rurais. Contudo, os resultados são inconclusivos com relação à decisão da família de inserir suas crianças no mercado de trabalho.

Um dos mais recentes esforços para o estudo do impacto dos programas de transferências de renda é realizado pelo Cedeplar em parceria com a Science - Associação Científica, que desenvolveram e executaram a Pesquisa de Avaliação de Impacto do Programa Bolsa Família (AIBF) na qual foram coletadas informações pertinentes para a análise de diferenciais entre famílias beneficiárias ou não do programa. Os tópicos pesquisados envolvem da- 
dos sobre consumo familiar, saúde, educação e trabalho dos integrantes da família. ${ }^{37}$ Resultados preliminares da pesquisa indicam que as famílias beneficiadas pelo Programa Bolsa Família apresentam impacto positivo sobre seus gastos de consumo, maior percentual de crianças que estudam e menor evasão escolar, e maior participação dos adultos no mercado de trabalho. ${ }^{38}$

Em resumo, a literatura especializada indica que os programas de transferência de renda são eficazes ao atender aos mais pobres e elevar a assiduidade escolar e médica a curto prazo. No entanto, ainda não há evidências consistentes sobre a eficácia dessas políticas no combate ao trabalho infantil sem a garantia de ações complementares na oferta de serviços de educação e saúde com qualidade.

\section{METODOLOGIA E BASE DE DADOS}

Para este trabalho utilizamos como base os microdados da Pesquisa Nacional por Amostra de Domicílios de 2004, que inclui o suplemento especial sobre Educação, segurança alimentar e acesso a transferências de renda e programas sociais. Consideramos apenas os domicílios classificados como particulares, excluindo-se os domicílios coletivos. Analisamos os dados, segundo os estratos de renda domiciliar por pessoa, excluída a renda proveniente de programas sociais. Em sequência, reduzimos a amostra para conter apenas os domicílios com crianças entre 5 e 15 anos de idade para analisar a incidência ou não de trabalho infantil; no entanto, a estimativa englobará crianças entre 7 e 15 anos, em virtude de a obrigatoriedade de frequência escolar ocorrer apenas no ensino fundamental. O modelo contemplará, ainda, a subdivisão espacial de acordo com as grandes regiões - Norte, Nordeste, Sudeste, Sul e Centro-Oeste - e as áreas censitárias de domicílio - urbano e rural.

A PNAD 2004 não fornece dados sobre o valor da renda familiar derivada dos programas sociais; portanto, utilizaremos a metodologia empregada por Fábio Veras Soares, Sergei Soares, Marcelo Medeiros e Rafael Guerreiro Osório (2006) para obtermos uma estimativa. ${ }^{39}$

Existem várias maneiras de modelar econometricamente a determinação do trabalho infantil, que depende, particularmente, das hipóteses sobre a tomada de decisão da família no que concerne à alocação do tempo do menor. Nesta pesquisa, assim como em estudos realizados anteriormente, 
optamos pelo uso da técnica do probit bivariado, que apresenta a característica de não impor qualquer formato específico para a tomada de decisão, mas de supor que as duas opções se relacionam entre si de alguma maneira. ${ }^{40} \mathrm{O}$ procedimento refere-se à definição de dois probits univariados estimados conjuntamente, permitindo que os resíduos de cada uma das regressões possam estar correlacionados. ${ }^{41}$ A forma estimada do probit bivariado é dada por:

$Y_{1 i}^{*}=\mathrm{X}_{1 i} \beta_{i}+\mu_{1 i} \quad Y_{1 i}=1$ se $Y_{1 i}^{*}>0 ; \quad Y_{1 i}=0$ caso contrário

$Y_{2 i}^{*}=\mathrm{X}_{2 i} \beta_{i}+\mu_{2 i} \quad Y_{2 i}=1$ se $Y^{*}{ }_{2 i}>0 ; \quad Y_{2 i}=0$ caso contrário

$E\left(\varepsilon_{1}\right)=E\left(\varepsilon_{2}\right)=0$

$\operatorname{Var}\left(\varepsilon_{1}\right)=\operatorname{Var}\left(\varepsilon_{2}\right)=1$

$\operatorname{Cov}\left(\varepsilon_{1}, \varepsilon_{2}\right)=\rho$

$\left(\varepsilon_{1}, \varepsilon_{2}\right) \sim \operatorname{BVN}(0,0,1,1, \rho)$

$X_{1}$ e $X_{2}$ representam os vetores explicativos referentes às crianças e pessoas de referência. ${ }^{42}$ Por sua vez, a primeira variável binária indica se a criança está matriculada na escola ou não, no momento da aplicação do questionário da PNAD, enquanto a segunda variável binária informa se a criança apresenta qualquer forma de ocupação na semana da entrevista. A escolha simultânea dessas duas opções implica quatro resultados diferentes e excludentes entre si: só estuda $\left(Y_{1 i}=1\right.$ e $\left.Y_{2 i}=0\right)$, estuda e trabalha $\left(Y_{1 i}=1\right.$ e $\left.Y_{2 i}=1\right)$, só trabalha $\left(Y_{1 i}=0\right.$ e $\left.Y_{2 i}=1\right)$ ou nenhum dos dois $\left(Y_{1 i}=0\right.$ e $\left.Y_{2 i}=0\right)$.

Se as duas decisões são correlacionadas, os erros dos dois modelos não são independentes entre si $\left(\rho=\operatorname{Cov}\left(\mu_{1 i}, \mu_{2 i}\right) \neq 0\right)$ e a probabilidade de uma opção depende da probabilidade da outra, sendo determinadas conjuntamente. Por outro lado, caso $\rho=0$, as escolhas de estudo e trabalho não têm relação entre si e os probits não precisam ser estimados conjuntamente. Além dos coeficientes $\beta_{1}$ e $\beta_{2}$, o probit bivariado fornece, também, a estimação da probabilidade prevista das quatro combinações possíveis apontadas anteriormente. Com base nessas estimativas, obtidas separadamente, por exemplo, para famílias com crianças beneficiárias do $\mathrm{PBF}$ - primeiro tipo - e para aquelas famílias que não são beneficiárias — segundo tipo —, calculamos a diferença entre a probabilidade de trabalhar e estudar das crianças nesses dois tipos de família. 


\section{IMPACTOS DO PROGRAMA BOLSA FAMÍLIA SOBRE O TRABALHO INFANTIL E A FREQUÊNCIA ESCOLAR}

No Brasil, em 2004, existiam 51 milhões e 800 mil domicílios particulares, dos quais cerca de 8,69 milhões são classificados em situação de pobreza, com renda por pessoa de até $\mathrm{R} \$ 100,00$. No restante de nosso trabalho, para efeitos de cálculo da renda por pessoa, deduzimos os rendimentos oriundos de programas de transferências de renda do total da renda domiciliar. Nesse sentido, o número de famílias pobres se eleva para 9 milhões e 445 mil domicílios, o que significa que pouco mais de 752 mil domicílios passam a se situar acima da linha de pobreza com o recebimento de benefícios. Ou seja, os programas federais de transferência de renda reduziram o percentual de domicílios considerados pobres em cerca de $8 \%$.

Por sua vez, a população de crianças e adolescentes com idade entre 5 e 15 anos é de 37,9 milhões, das quais 2,7 milhões exercem algum tipo de trabalho, representando $7,3 \%$ do total dessa faixa etária, enquanto 1,2 milhão de jovens com idade escolar — 3,9\% — não frequentam o sistema escolar. Assim, dos jovens com idade entre 7 a 15 anos, temos que 88,3\% apenas estudam, 7,8\% estudam e trabalham, $1 \%$ só trabalha e $2,9 \%$ não estudam nem trabalham (tabela 1).

Com relação aos domicílios, 23 milhões apresentam pelo menos uma pessoa entre 5 e 15 anos entre os seus moradores, constatando-se a ocorrência de trabalho infantil em 2,1 milhões deles - 9,4\% do total, e o não atendimento escolar de ao menos uma criança em 1,7\% dos domicílios. Nesse recorte, 6,8 milhões $(29,8 \%)$ apresentam renda familiar por pessoa inferior a R\$100,00, dos quais 3,6 milhões são beneficiárias do Bolsa Família, repre-

Tabela 1: Distribuição da população com idade entre 7 e 15 anos, segundo participação no mercado de trabalho e sistema escolar, Brasil 2004

\begin{tabular}{lccc}
\hline & Estuda & Não estuda & Total \\
\hline Não trabalha & 27.515 .539 & 917.755 & 28.433 .294 \\
\hline$\%$ & 88,27 & 2,94 & 91,22 \\
\hline Trabalha & 2.439 .127 & 298.253 & 2.737 .380 \\
\hline$\%$ & 7,83 & 0,96 & 8,78 \\
\hline Total & 29.954 .666 & 1.216 .008 & 31.170 .674 \\
\hline$\%$ & 96,10 & 3,90 & 100,0 \\
\hline
\end{tabular}

Fonte: IBGE - PNAD (2004). Elaboração própria. 
Tabela 2: Distribuição dos domicílios pobres com crianças com idade entre 5 e 15 anos, segundo incidência de trabalho infantil e recebimento do Bolsa Família, Brasil 2004

\begin{tabular}{lccc}
\hline & Sem trabalho infantil & Com trabalho infantil & Total \\
\hline Não recebe Bolsa Família & 2.884 .854 & 323.478 & 3.208 .332 \\
\hline$\%$ & 41,91 & 4,70 & 46,61 \\
\hline Recebe Bolsa Família & 3.004 .591 & 670.926 & 3.675 .517 \\
\hline$\%$ & 43,65 & 9,75 & 53,39 \\
\hline Total & 5.889 .445 & 994.404 & 6.883 .849 \\
\hline$\%$ & 85,55 & 14,45 & 100,00 \\
\hline Fonte: IBGE - PNAD (2004). Elaboração própria.
\end{tabular}

sentando pouco mais da metade dos domicílios pobres (53,4\%). É interessante notar que, segundo a tabela 2 , há um conjunto de domicílios pobres que, mesmo sem receber benefícios, não emprega o trabalho de suas crianças para complementar a renda familiar.

O quadro 1 apresenta uma síntese dos resultados estimados pelo probit bivariado para a amostra total, ${ }^{43}$ ratificando os resultados apresentados pela literatura especializada. ${ }^{44}$ A probabilidade de incidência de trabalho infantil é maior entre meninos, aumentando com a idade da criança, o tamanho da família, o fato de o domicílio localizar-se na área rural e o chefe do domicílio estar ocupado informalmente, bem como o seu cônjuge também estar em alguma forma de ocupação. Por outro lado, o fato de a pessoa de referência do domicílio ser homem, o aumento da escolaridade - tanto dos pais como das crianças - e da renda familiar agem contra o fenômeno.

No entanto, o resultado mais interessante se revela no coeficiente positivo para a variável Bolsa Família, indicando que ser beneficiário do programa eleva as chances de incidência de trabalho infantil nos domicílios pobres. Contudo, é necessário ressaltar que o combate ao trabalho das crianças não faz parte do escopo do programa, sem contar que seus beneficiários comumente se constituem de famílias pobres que necessitam da renda oriunda do trabalho de suas crianças para garantir sua sobrevivência.

Com relação à frequência escolar, observamos que o tamanho da família e os aumentos na idade da criança afetam negativamente o atendimento escolar, enquanto elevações na escolaridade dos pais e das crianças, da renda domiciliar per capita, bem como o recebimento do Bolsa Família aumentam as chances de a criança frequentar a escola. 
Quadro 1: Impacto das variáveis sobre a incidência de trabalho infantil e frequência escolar, Brasil 2004

\begin{tabular}{|c|c|c|}
\hline Variáveis & Estudar & Trabalhar \\
\hline sexo_pr & + & - \\
\hline idade_pr & + & NS \\
\hline cor_pr & NS & NS \\
\hline est_pr & + & - \\
\hline dum_sc & - & + \\
\hline dum_cp & NS & + \\
\hline dum_ep & NS & + \\
\hline dum_ot & NS & + \\
\hline dum_ds & - & - \\
\hline sexo_fi & NS & + \\
\hline idade_fi & - & + \\
\hline cor_fi & NS & NS \\
\hline est_fi & + & - \\
\hline ocup_cj & + & + \\
\hline tam_fam & - & + \\
\hline rd_dm_pc & + & NS \\
\hline bf & + & + \\
\hline Rural & - & + \\
\hline Norte & - & + \\
\hline Nordeste & NS & + \\
\hline Sul & - & + \\
\hline Centro-Oeste & - & + \\
\hline
\end{tabular}

Fonte: IBGE - PNAD (2004). Elaboração própria.

+: efeito positivo para a ocorrência do fenômeno;

-: efeito negativo para a ocorrência do fenômeno;

NS: não significante, sem efeito sobre o fenômeno.

Em termos geográficos, temos que, com exceção do Nordeste, em todas as demais regiões as crianças entre 7 e 15 anos apresentam probabilidades menores de estudar que as crianças da mesma faixa etária que residem no Sudeste. Quanto à probabilidade de trabalhar, estar fora da região Sudeste amplia essa possibilidade.

A tabela 3 apresenta as probabilidades estimadas para cada uma das possíveis combinações entre as opções de estudar e trabalhar dos jovens. Observamos que, entre os domicílios pobres, $85 \%$ dos jovens apenas estudam, $1,7 \%$ apenas trabalha e $9,1 \%$ estudam e trabalham. Por outro lado, há $4,1 \%$ de chances de os jovens se apresentarem em situação marginalizada, fora tanto do sistema escolar como do mercado de trabalho. 
Tabela 3: Probabilidades estimadas para a incidência de trabalho infantil e frequência escolar. Brasil 2004 (em \%)

\begin{tabular}{lc}
\hline Só estuda & 85,0 \\
\hline Estuda e trabalha & 9,1 \\
\hline Só trabalha & 1,7 \\
\hline Não estuda nem trabalha & 4,1 \\
\hline Fonte: IBGE - PNAD (2004). Elaboração própria.
\end{tabular}

Os quadros 2 e 3 apresentam o sumário dos resultados do probit bivariado para os recortes geográfico e censitário. Em relação à estimação obtida para a amostra total, não houve alterações nos sinais dos coeficientes, ou seja, os efeitos positivos ou negativos de cada uma das variáveis do modelo para a incidência de trabalho infantil e a frequência escolar não são conflitantes de acordo com a localização do domicílio. Destarte, as mudanças ocorrem no nível da significância dos coeficientes, isto é, variáveis que influenciam a ocorrência dos fenômenos analisados para a amostra total podem deixar de ter esse papel para recortes distintos, e vice-versa.

O recorte censitário analisa os domicílios segundo sua localização censitária - urbano e rural. Nesse sentido, observamos que, nos domicílios em áreas urbanas, a elevação da idade dos pais passa a influenciar negativamente a incidência do trabalho infantil, enquanto a renda domiciliar per capita não apresenta impactos sobre o fenômeno. Ressaltamos que o estudo analisa apenas domicílios com renda per capita inferior a $\mathrm{R} \$ 260,00$, ou seja, é esperado que, se a amostra considerasse os demais domicílios, o papel da variável renda seria mais evidente. Com relação ao atendimento escolar, duas variáveis passam a ser significantes: cor da pessoa de referência e sexo da criança. O sinal negativo da variável cor indica que pais que se autoidentificam como negros ou pardos apresentam menor probabilidade de enviar seus filhos para a escola, enquanto o fato de a criança ser do sexo masculino eleva essa probabilidade.

Por sua vez, os domicílios localizados em áreas rurais passam a apresentar um maior número de variáveis que não influenciam a frequência escolar das crianças, como a renda domiciliar per capita, o sexo e a idade da pessoa de referência. A variável Bolsa Família mostra que ser beneficiário do programa continua ampliando as possibilidades de a criança trabalhar e estudar, independente da área censitária em que ela se encontra. 
Quadro 2: Impacto das variáveis sobre a incidência de trabalho infantil e frequência escolar, segundo área censitária, Brasil 2004

\begin{tabular}{|c|c|c|c|c|}
\hline \multirow[b]{2}{*}{ Variáveis } & \multicolumn{2}{|c|}{ Trabalhar } & \multicolumn{2}{|c|}{ Estudar } \\
\hline & Urbano & Rural & Urbano & Rural \\
\hline sexo_pr & - & - & + & NS \\
\hline idade_pr & - & NS & + & NS \\
\hline cor_pr & NS & NS & - & NS \\
\hline est_pr & - & - & + & + \\
\hline dum_sc & + & + & - & - \\
\hline dum_cp & + & + & NS & - \\
\hline dum_ep & + & + & NS & NS \\
\hline dum_ot & + & + & NS & NS \\
\hline dum_ds & NS & NS & - & NS \\
\hline sexo_fi & + & + & + & NS \\
\hline idade_fi & + & + & - & - \\
\hline cor_fi & NS & NS & NS & NS \\
\hline est_fi & - & - & + & + \\
\hline ocup_cj & + & + & + & + \\
\hline tam_fam & + & + & - & - \\
\hline rd_dm_pc & NS & - & + & NS \\
\hline$\underline{\mathrm{Bf}}$ & + & + & + & + \\
\hline Norte & NS & + & NS & NS \\
\hline Nordeste & + & NS & NS & + \\
\hline Sul & + & + & - & NS \\
\hline Centro-Oeste & + & + & - & NS \\
\hline
\end{tabular}

Fonte: IBGE - PNAD (2004). Elaboração própria.

+: efeito positivo para a ocorrência do fenômeno;

-: efeito negativo para a ocorrência do fenômeno;

NS: não significante, sem efeito sobre o fenômeno.

Ademais, as principais diferenças nas estimações por grandes regiões geográficas em relação ao resultado obtido para o Brasil se referem à significância das variáveis (quadro 3). No que diz respeito às diferenças do impacto de ser ou não beneficiário do Bolsa Família nas grandes regiões geográficas, temos que apenas no Nordeste e no Sudeste o programa afeta tanto a probabilidade de estudar quanto de trabalhar (ambas positivamente). Nas regiões Norte e Centro-Oeste, as crianças beneficiárias do programa têm mais possibilidades de estudar, mas isso não interfere nas chances de trabalhar. A região Sul é a única onde o Programa Bolsa Família não traz nenhum impacto tanto sobre a probabilidade de estudar quanto de trabalhar.

Calculamos o impacto de mudanças marginais nas variáveis explicativas $x_{k}$ sobre as quatro probabilidades obtidas na estimação do probit bivariado: 
Quadro 3: Impacto das variáveis sobre a incidência de trabalho infantil e frequência escolar, segundo regiões geográficas, Brasil 2004

\begin{tabular}{|c|c|c|c|c|c|c|c|c|c|c|}
\hline \multirow[b]{2}{*}{ Variáveis } & \multirow[b]{2}{*}{ Norte } & \multicolumn{3}{|c|}{ Estudar } & \multirow[b]{2}{*}{ Centro-Oeste } & \multirow[b]{2}{*}{ Norte } & \multicolumn{2}{|c|}{ Trabalhar } & \multirow[b]{2}{*}{ Sul } & \multirow[b]{2}{*}{ Centro-Oeste } \\
\hline & & Nordeste & Sudeste & Sul & & & Nordeste & Sudeste & & \\
\hline sexo_pr & NS & + & + & NS & NS & - & - & - & - & - \\
\hline idade_pr & + & + & + & NS & NS & NS & NS & NS & NS & NS \\
\hline cor_pr & NS & NS & NS & NS & NS & NS & NS & NS & NS & NS \\
\hline est_pr & + & + & + & NS & + & - & - & - & - & - \\
\hline dum_sc & - & - & NS & - & NS & NS & + & NS & NS & + \\
\hline dum_cp & NS & NS & NS & NS & NS & + & + & + & + & + \\
\hline dum_ep & NS & NS & NS & NS & NS & + & + & + & + & NS \\
\hline dum_ot & NS & - & NS & NS & NS & NS & + & + & + & + \\
\hline dum_ds & NS & - & NS & NS & NS & NS & NS & NS & NS & NS \\
\hline sexo_fi & NS & NS & + & NS & NS & + & + & + & + & + \\
\hline idade_fi & - & - & - & - & - & + & + & + & + & + \\
\hline cor_fi & NS & NS & NS & NS & NS & NS & NS & + & NS & NS \\
\hline est_fi & + & + & + & + & + & - & - & NS & NS & NS \\
\hline ocup_cj & + & + & NS & NS & + & + & + & + & + & + \\
\hline tam_fam & - & - & - & - & - & + & + & + & + & + \\
\hline Rd_dm_pc & NS & + & + & + & NS & NS & - & NS & NS & + \\
\hline bf & + & + & + & NS & + & NS & + & + & NS & NS \\
\hline rural & - & NS & - & NS & NS & + & + & + & + & + \\
\hline
\end{tabular}

Fonte: IBGE - PNAD (2004). Elaboração própria.

+: efeito positivo para a ocorrência do fenômeno;

-: efeito negativo para a ocorrência do fenômeno;

NS: não significante, sem efeito sobre o fenômeno.

só estuda, estuda e trabalha, só trabalha ou nenhum dos dois. Os efeitos marginais (as variações percentuais da probabilidade de o evento ocorrer quando uma determinada variável independente é modificada) são calculados a partir dos coeficientes estimados $\widehat{\beta}_{1}$ e $\widehat{\beta}_{2}$. Estamos interessados particularmente no efeito marginal da variável Bolsa Família sobre quatro probabilidades obtidas no probit bivariado. Como essa variável é discreta, o efeito marginal mede a diferença entre a probabilidade de a criança participar ou não do programa. ${ }^{45} \mathrm{~A}$ tabela 4 apresenta o efeito marginal da variável Bolsa Família por área censitária e as grandes regiões.

Esses dados qualificam o resultado obtido pela estimação do probit bivariado, em que se encontrou que a participação da criança no programa aumenta tanto a probabilidade de ela estudar quanto de trabalhar. No entanto, os resultados obtidos da combinação dos dois probits estimados conjuntamente mostram que um dos méritos do programa é a queda não desprezível 
Tabela 4: Efeito marginal para as possíveis combinações entre estudo e trabalho, segundo área de situação censitária e grandes regiões (em \%)

\begin{tabular}{|c|c|c|c|c|}
\hline & \multicolumn{2}{|c|}{ Estuda e } & \multicolumn{2}{|c|}{ Não estuda } \\
\hline & Só estuda & Trabalha & Só trabalha & nem trabalha \\
\hline \multicolumn{5}{|l|}{ Brasil } \\
\hline Rural & 1,32 & 4,02 * & $-1,36$ * & $-3,98$ * \\
\hline Urbano & 1,15 * & 1,01 * & $-0,14$ * & $-2,02$ * \\
\hline Total & 1,36 * & 1,37 * & $-0,24$ * & $-2,49$ * \\
\hline \multicolumn{5}{|l|}{ Regiões } \\
\hline Norte & 3,47 * & 0,36 & $-0,50$ * & $-3,33 *$ \\
\hline Nordeste & $1,59 * *$ & $2,21 *$ & $-0,36$ * & $-3,45$ * \\
\hline Sudeste & $-0,14$ & $1,61 *$ & $-0,04$ & $-1,44$ * \\
\hline Sul & $-0,86$ & 1,34 & 0,03 & $-0,50$ \\
\hline Centro-Oeste & $2,32 * *$ & 0,30 & $-0,31 *$ & $-2,30$ * \\
\hline \multicolumn{5}{|c|}{ Fonte: IBGE - PNAD (2004). Elaboração própria. } \\
\hline \multicolumn{5}{|c|}{ * Significativo ao nível de confiança de $1 \%$. } \\
\hline \multicolumn{5}{|c|}{ ** Significativo ao nível de confiança de 5\%. } \\
\hline *** Significativo a & nfiança de $10 \%$ & & & \\
\hline
\end{tabular}

da ociosidade das crianças. O maior efeito do Programa Bolsa família é a redução de 2,50\% (Brasil) na probabilidade de a criança não estudar e nem trabalhar. Essa redução chega a 4\% quando se trata da área rural. Em relação às regiões geográficas, constata-se uma redução da ociosidade de aproximadamente 3,5\% no Norte e Nordeste do país.

As chances de a criança sair da atividade trabalhadora ou da ociosidade e somente estudar também existem. A tabela 4 mostra que, de maneira geral, no Brasil, a chance de a criança somente estudar aumenta em 1,36\% se ela participar do programa, mas na área rural do país essa probabilidade não é significativamente diferente de zero. Em termos regionais, o maior impacto do programa na possibilidade de a criança só estudar ocorre na região Norte (3,5\%), seguida do Centro-Oeste (2,3\%) e do Nordeste (1,6\%).

\section{CONSIDERAÇÕES FINAIS}

O Programa Bolsa Família se constitui na ação que contempla o maior número de beneficiários e de volume de recursos no âmbito do Fome Zero, consistindo em uma das modalidades de programa de transferência de renda com condicionalidade recomendada pelas agências multilaterais. ${ }^{46}$ A curto prazo, o PBF busca ampliar o atendimento escolar às crianças e estender os cuidados primários de saúde às famílias mais pobres, enquanto a 
longo prazo visa a romper o ciclo da pobreza entre gerações por meio da incorporação de capital humano e consequente maior e melhor oportunidade de inserção no mercado de trabalho. Ressalva-se que, em um primeiro momento, a transferência monetária direta pode diminuir os índices de pobreza e de desigualdade de renda; no entanto, a eficácia das condicionalidades para romper a transmissão da pobreza entre gerações, ou seja, o efeito positivo de longo prazo do programa, dependerá da oferta de melhor qualidade dos serviços de educação e de saúde.

Posto isso, as estimações realizadas neste trabalho corroboram os resultados apresentados por diversos estudos sobre o trabalho infantil e a frequência escolar das crianças, dos quais destacamos: a cor das pessoas — pais e filhos — não é determinante para a ocorrência de trabalho infantil ou para o atendimento escolar; elevações da renda familiar e de níveis de escolaridade apresentam resultados positivos sobre os fenômenos estudados; pais ocupados em trabalhos informais tendem a utilizar mais a força de trabalho de suas crianças, no entanto, apresentam algumas evidências positivas para a frequência escolar; os rapazes mais velhos das famílias apresentam maiores probabilidades de estarem ocupados, mas o gênero dos jovens não apresenta influência para a frequência escolar; e quanto maior o tamanho da família, maiores as chances de haver trabalho infantil, e não atendimento escolar.

Desse modo, os resultados indicam que o programa é eficiente em atingir um de seus objetivos fundamentais: elevar o atendimento escolar das crianças. Por outro lado, é incapaz de reduzir a incidência de trabalho infantil, fenômeno perverso intrinsecamente relacionado com o menor atendimento escolar entre crianças de famílias pobres. Ressaltamos que o combate ao trabalho infantil não é uma das metas do programa, apesar de se tratar de um fenômeno intrínseco à baixa renda das famílias. Assim, alguns aprimoramentos do PBF atacariam, indiretamente, essa questão.

Primeiramente, o PBF poderia reproduzir ações de sucesso já existentes, como a Jornada Ampliada oferecida pelo Peti, período extracurricular em que o aluno tem oportunidade de participar de atividades artísticas, culturais, esportivas, profissionalizantes e de reforço pedagógico, de modo que são reduzidas as horas que as crianças poderiam dedicar ao trabalho. Assim, ao se elevar o número de horas em que as crianças permanecem na escola, tem-se, consequentemente, uma redução das horas disponíveis para o trabalho, além de fornecer uma formação mais ampla para os jovens. 
Ademais, considerando que famílias beneficiárias do PBF possuem, em geral, rendas extremamente baixas, de modo que rendimentos provenientes do trabalho das crianças são muitas vezes essenciais para a sobrevivência dela e de seus familiares, e que a dificuldade de acesso às escolas, em especial nas áreas rurais, é fator que favorece a maior incidência de trabalho infantil, simples e incipientes transferências de recursos não são capazes de erradicar essa problemática. Portanto, a curto prazo as condicionalidades do programa são uma forma eficiente de se criarem externalidades positivas; contudo, é vital que se realizem, em conjunto, ações complementares de melhorias da oferta de serviços escolares e saúde, além de políticas de geração de emprego, renda e capacitação para os pais, ou seja, investimentos sustentáveis para elevação do capital humano e redução da pobreza a longo prazo.

\section{APÊNDICE 1}

\section{Descrição das variáveis utilizadas no modelo probit bivariado}

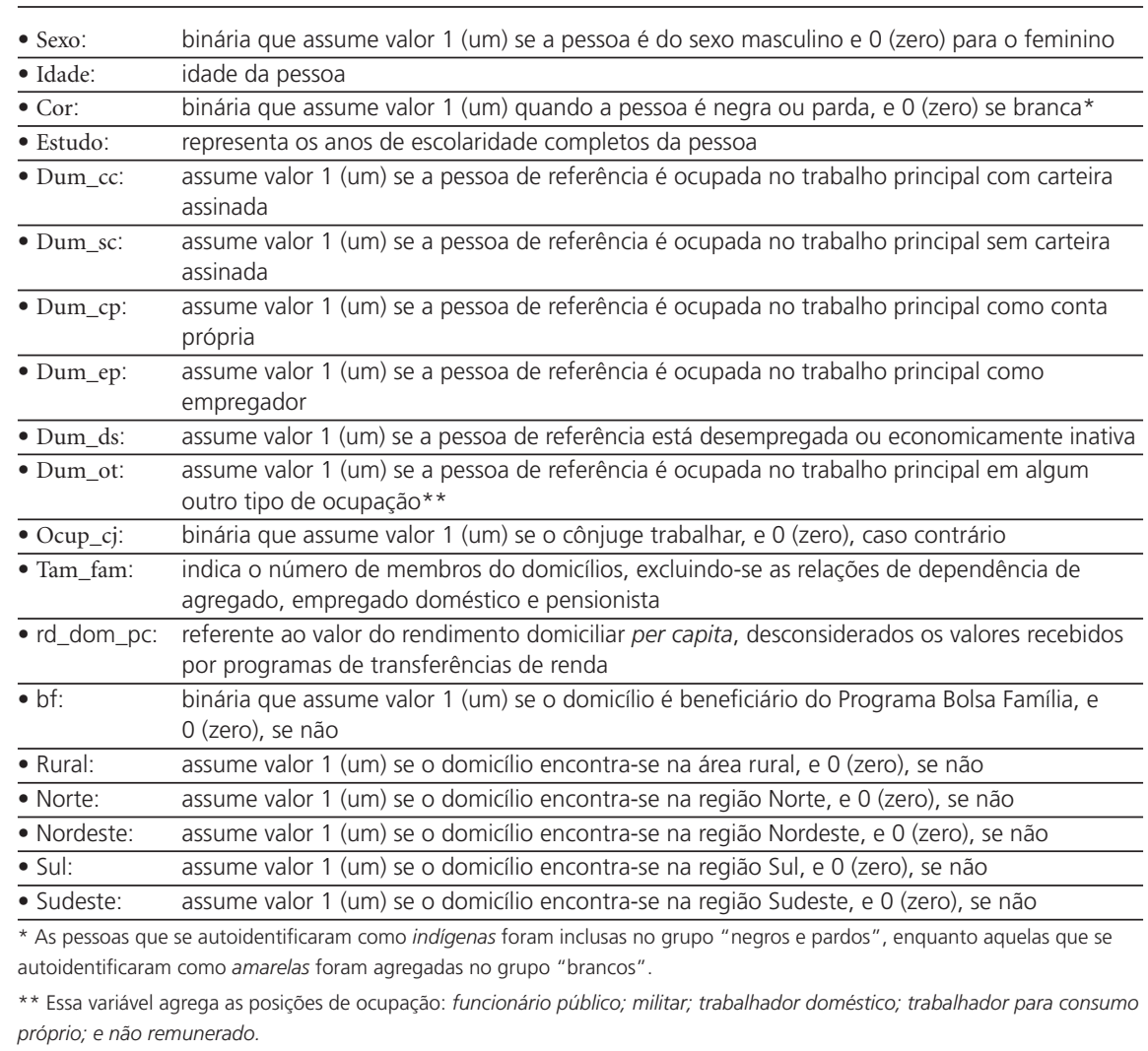


APÊNDICE 2

Tabela A1: Estimações do probit bivariado. Crianças entre 7 e 15 anos, Brasil 2004

\begin{tabular}{|c|c|c|c|}
\hline Variáveis & Coef. & Std. Err. & Sign. \\
\hline $\begin{array}{l}\text { Trabalhar } \\
\text { sexo_pr }\end{array}$ & $-0,27343$ & 0,03096 & * \\
\hline idade_pr & $-0,00137$ & 0,00113 & \\
\hline cor_pr & 0,00151 & 0,03006 & \\
\hline est_pr & $-0,03562$ & 0,00385 & * \\
\hline OC_SC & 0,18297 & 0,04012 & * \\
\hline oc_cp & 0,52709 & 0,03425 & * \\
\hline oc_ep & 0,66286 & 0,07492 & * \\
\hline OC_ot & 0,24215 & 0,04554 & * \\
\hline OC_ds & $-0,03814$ & 0,04571 & \\
\hline sexo_fi & 0,44709 & 0,02268 & * \\
\hline idade_fi & 0,22150 & 0,00719 & * \\
\hline cor_fi & 0,02637 & 0,03041 & \\
\hline est_fi & $-0,02037$ & 0,00696 & * \\
\hline ocup_cj & 0,43157 & 0,02385 & * \\
\hline tam_fam & 0,04342 & 0,00590 & * \\
\hline rd_dm_pc & $-0,00016$ & 0,00020 & \\
\hline bf & 0,09085 & 0,02364 & * \\
\hline rural & 0,66172 & 0,02489 & * \\
\hline Norte & 0,11665 & 0,03808 & * \\
\hline Nordeste & 0,12307 & 0,03224 & * \\
\hline Sul & 0,24807 & 0,04004 & * \\
\hline Centro-Oeste & 0,18300 & 0,04442 & * \\
\hline _cons & $-4,74445$ & 0,10335 & * \\
\hline \multicolumn{4}{|l|}{ Estudar } \\
\hline sexo_pr & 0,10846 & 0,03220 & * \\
\hline idade_pr & 0,00557 & 0,00125 & * \\
\hline cor_pr & $-0,04384$ & 0,03364 & \\
\hline est_pr & 0,04385 & 0,00430 & * \\
\hline OC_SC & $-0,20216$ & 0,04123 & * \\
\hline oc_cp & $-0,02954$ & 0,03879 & \\
\hline oc_ep & 0,01492 & 0,10630 & \\
\hline OC_ot & $-0,05490$ & 0,04949 & \\
\hline OC_ds & $-0,10905$ & 0,04485 & * \\
\hline sexo_fi & 0,03158 & 0,02469 & \\
\hline idade_fi & $-0,23640$ & 0,00765 & * \\
\hline cor_fi & $-0,03145$ & 0,03397 & \\
\hline est_fi & 0,19564 & 0,00827 & * \\
\hline ocup_cj & 0,10880 & 0,02809 & * \\
\hline tam_fam & $-0,06677$ & 0,00635 & * \\
\hline
\end{tabular}


(continuação tabela A1)

\begin{tabular}{lccc}
\hline Variáveis & Coef. & Std. Err. & Sign. \\
\hline $\begin{array}{l}\text { Trabalhar } \\
\text { rd_dm_pc }\end{array}$ & 0,00093 & 0,00023 & $*$ \\
\hline $\begin{array}{l}\text { Variáveis } \\
\text { Estudar }\end{array}$ & Coef. & Std. Err. & Sign. \\
\hline bf & 0,30343 & 0,02786 & $*$ \\
\hline rural & $-0,08257$ & 0,03103 & $*$ \\
\hline Norte & $-0,07940$ & 0,04117 & $* *$ \\
\hline Nordeste & 0,03952 & 0,03540 & $*$ \\
\hline Sul & $-0,15549$ & 0,04594 & $* *$ \\
\hline Centro-Oeste & $-0,08379$ & 0,04766 & $*$ \\
\hline cons & 3,42614 & 0,10415 & $*$ \\
\hline athrho & $-0,22426$ & 0,01972 & \\
rho & $-0,22057$ & 0,01876 & \\
\hline
\end{tabular}

\begin{tabular}{lr}
\hline No. Obs & 30.288 \\
\hline$P(1,0)$ & 89,94 \\
\hline$P(1,1)$ & 5,61 \\
\hline$P(0,1)$ & 0,61 \\
\hline$P(0,0)$ & 3,85 \\
\hline
\end{tabular}

OBS.: A extensão fi significa que a variável refere-se a criança e a extensão pr diz respeito à pessoa de referência.

* Significativo no nível de confiança de $1 \%$.

** Significativo no nível de confiança de $5 \%$.

*** Significativo no nível de confiança de $10 \%$.

Tabela A2: Estimações do probit bivariado, segundo áreas de situação censitária. Crianças entre 7 e 15 anos, Brasil 2004

\begin{tabular}{|c|c|c|c|c|c|c|}
\hline \multirow[b]{2}{*}{ Variáveis } & \multicolumn{3}{|c|}{ Urbano } & \multicolumn{3}{|c|}{ Rural } \\
\hline & Coef. & Std. Err. & Sign. & Coef. & Std. Err. & Sign. \\
\hline $\begin{array}{l}\text { Trabalhar } \\
\text { sexo_pr }\end{array}$ & $-0,23075$ & 0,03386 & * & $-0,42714$ & 0,07389 & * \\
\hline idade_pr & $-0,00368$ & 0,00141 & * & 0,00248 & 0,00192 & \\
\hline cor_pr & 0,00806 & 0,03648 & & $-0,00719$ & 0,05280 & \\
\hline est_pr & $-0,03674$ & 0,00430 & * & $-0,04225$ & 0,00836 & * \\
\hline OC_SC & 0,18534 & 0,04681 & * & 0,25998 & 0,07776 & * \\
\hline Oc_cp & 0,41424 & 0,03981 & * & 0,71826 & 0,07068 & * \\
\hline oc_ep & 0,63877 & 0,08905 & * & 0,76749 & 0,13789 & * \\
\hline OC_ot & 0,21263 & 0,05125 & * & 0,32109 & 0,09489 & * \\
\hline OC_ds & $-0,02109$ & 0,04947 & & $-0,14789$ & 0,10902 & \\
\hline sexo_fi & 0,34955 & 0,02745 & * & 0,63425 & 0,03955 & * \\
\hline idade_fi & 0,20837 & 0,00925 & * & 0,24511 & 0,01178 & * \\
\hline cor_fi & 0,04750 & 0,03670 & & $-0,01360$ & 0,05426 & \\
\hline est_fi & $-0,01766$ & 0,00865 & ** & $-0,02649$ & 0,01218 & ** \\
\hline ocup_cj & 0,32158 & 0,02887 & * & 0,63416 & 0,04669 & * \\
\hline tam_fam & 0,04368 & 0,00732 & * & 0,04592 & 0,01024 & * \\
\hline
\end{tabular}


(continuação tabela A2)

\begin{tabular}{|c|c|c|c|c|c|c|}
\hline rd_dm_pc & 0,00030 & 0,00025 & & $-0,00090$ & 0,00037 & $* *$ \\
\hline bf & 0,09251 & 0,02936 & * & 0,08994 & 0,04065 & $\star *$ \\
\hline Norte & 0,04780 & 0,04592 & & 0,24358 & 0,07343 & * \\
\hline Nordeste & 0,15525 & 0,03661 & * & 0,09726 & 0,06457 & \\
\hline Sul & 0,10298 & 0,04962 & * & 0,54252 & 0,07774 & * \\
\hline Centro-Oeste & 0,15882 & 0,04972 & * & 0,24848 & 0,09212 & * \\
\hline _cons & $-4,42181$ & 0,12647 & * & $-4,71652$ & 0,18708 & * \\
\hline $\begin{array}{l}\text { Estudar } \\
\text { sexo_pr }\end{array}$ & 0,13240 & 0,03571 & * & $-0,01486$ & 0,08058 & \\
\hline idade_pr & 0,00757 & 0,00150 & * & 0,00068 & 0,00236 & \\
\hline cor_pr & $-0,09000$ & 0,03904 & $* *$ & 0,07696 & 0,06617 & \\
\hline est_pr & 0,04693 & 0,00475 & * & 0,02421 & 0,01072 & $* *$ \\
\hline OC_SC & $-0,14848$ & 0,04857 & * & $-0,37052$ & 0,08668 & * \\
\hline OC_cp & 0,01096 & 0,04511 & & $-0,17639$ & 0,08412 & $\star *$ \\
\hline oc_ep & 0,03534 & 0,13160 & & $-0,05399$ & 0,18685 & \\
\hline OC_ot & $-0,02366$ & 0,05585 & & $-0,13874$ & 0,11301 & \\
\hline Oc_ds & $-0,08831$ & 0,04922 & $* * *$ & $-0,16884$ & 0,11745 & \\
\hline sexo_fi & 0,06081 & 0,02912 & $* *$ & $-0,03433$ & 0,04745 & \\
\hline idade_fi & $-0,24890$ & 0,00911 & * & $-0,21271$ & 0,01410 & * \\
\hline cor_fi & $-0,00303$ & 0,03905 & & $-0,11131$ & 0,06895 & \\
\hline est_fi & 0,20753 & 0,00988 & * & 0,17009 & 0,01531 & * \\
\hline ocup_cj & 0,10863 & 0,03347 & * & 0,12468 & 0,05306 & * \\
\hline tam_fam & $-0,08212$ & 0,00759 & * & $-0,03344$ & 0,01142 & * \\
\hline rd_dm_pc & 0,00110 & 0,00027 & * & 0,00032 & 0,00045 & \\
\hline bf & 0,28145 & 0,03314 & * & 0,37945 & 0,05038 & * \\
\hline Norte & $-0,07213$ & 0,04796 & & $-0,03457$ & 0,08480 & \\
\hline Nordeste & 0,01251 & 0,04024 & & 0,12734 & 0,07626 & $* * *$ \\
\hline Sul & $-0,20074$ & 0,05235 & * & 0,08153 & 0,09989 & \\
\hline Centro-Oeste & $-0,11676$ & 0,05333 & $* *$ & 0,07961 & 0,11009 & \\
\hline _cons & 3,47998 & 0,12309 & * & 3,36031 & 0,20217 & * \\
\hline $\begin{array}{l}\text { athrho } \\
\text { rho }\end{array}$ & $\begin{array}{l}-0,18591 \\
-0,18379\end{array}$ & $\begin{array}{l}0,03300 \\
0,03188\end{array}$ & * & $\begin{array}{l}-0,18591 \\
-0,18379\end{array}$ & $\begin{array}{l}0,03300 \\
0,03188\end{array}$ & * \\
\hline No. Obs = & 23.798 & & & 6.490 & & \\
\hline Wald chi2 (42) = & $=2.932$ & & & 1.825 & & \\
\hline Prob. $>$ chi $2=$ & 0,0000 & & & 0,0000 & & \\
\hline
\end{tabular}

Fonte: IBGE - PNAD (2004). Elaboração própria.

* Significativo no nível de confiança de $1 \%$.

** Significativo no nível de confiança de $5 \%$.

*** Significativo no nível de confiança de $10 \%$. 


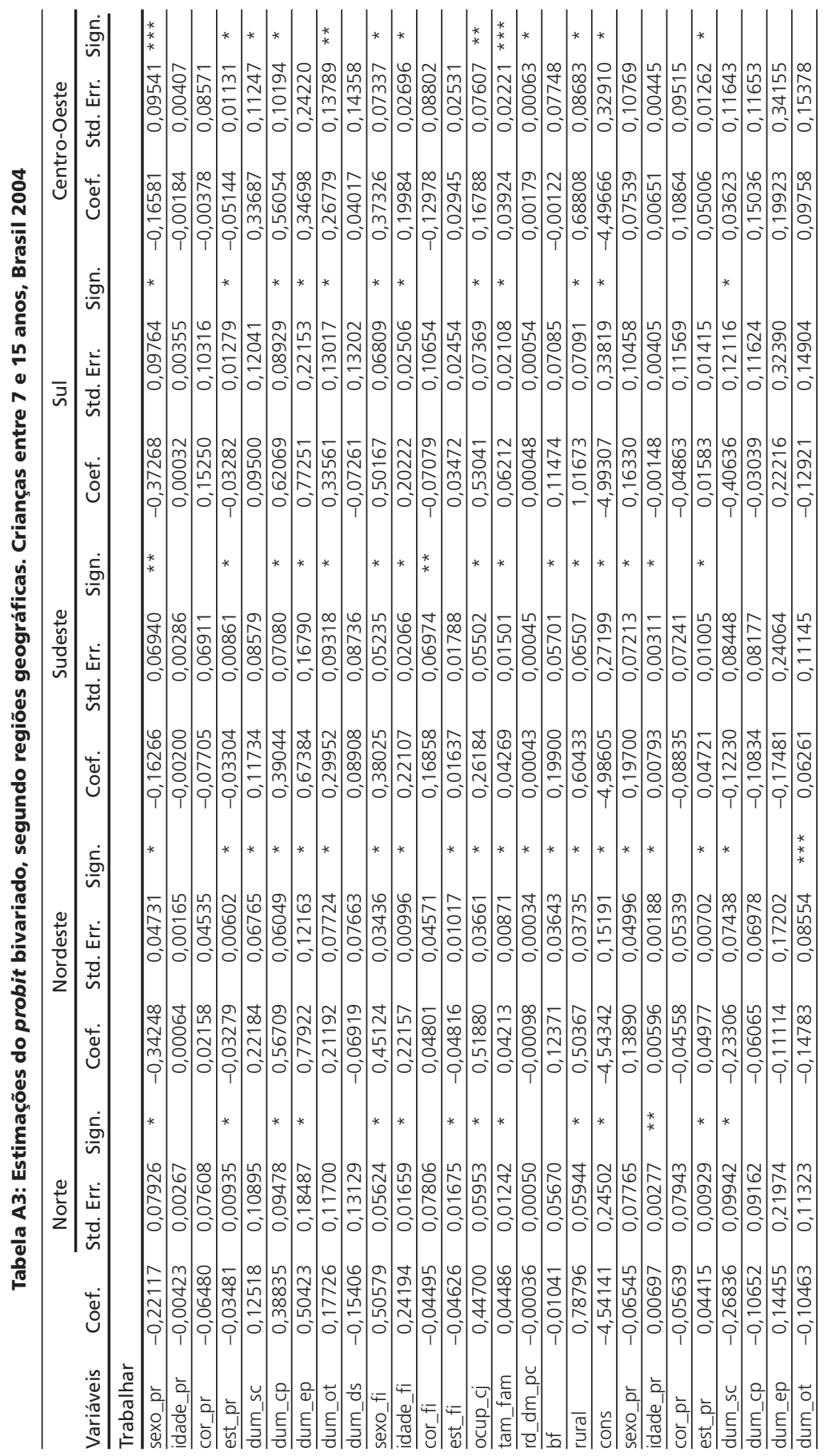




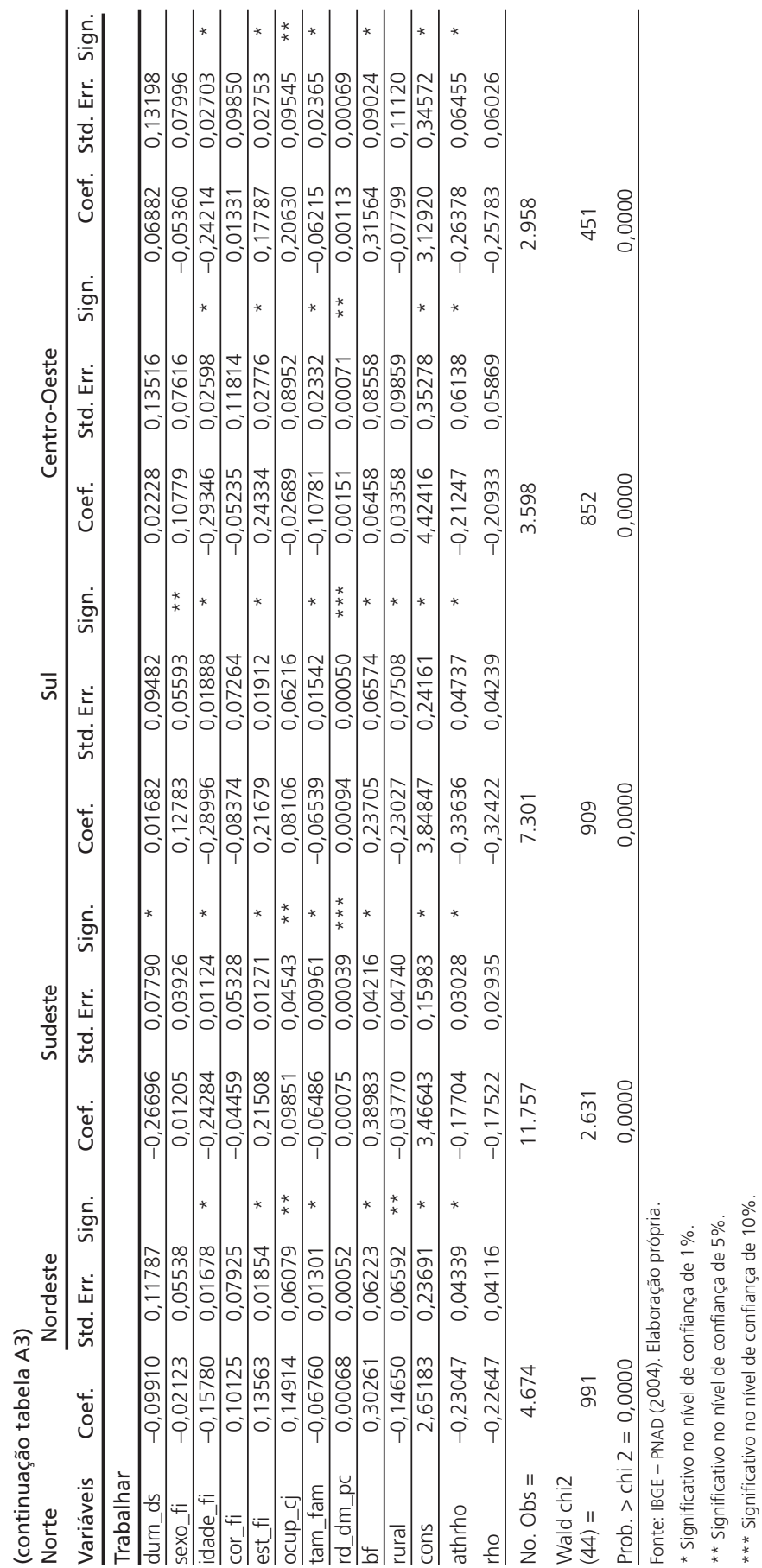




\section{NOTAS}

1. Para efeitos deste estudo, consideramos trabalho infantil qualquer forma de ocupação exercida pela população entre 5 e 15 anos de idade, seja ela remunerada ou não, inclusive o trabalho para consumo próprio; enquanto frequência escolar se refere às crianças com idade entre 7 e 15 anos matriculadas na rede de ensino.

2. No conceito mais utilizado entre economistas, pobreza representa a insuficiência de renda do indivíduo e/ou de sua família. Contudo, diversos autores sugerem que o termo deveria compreender não apenas a questão de baixos rendimentos, mas uma maior gama de necessidades, como insuficiências materiais e de oportunidades. Esse tema é tratado, por exemplo, em Chambers, R. What is poverty? Who asks? Who answers? In: Poverty in Focus. What is poverty? Concepts and measures. Brasília: IPC, dez. 2006.

3. Perry, G. E.; Arias, O. S.; López, J. H.; Maloney, W. F.; Servén, L. Poverty reduction and growth: virtuous and vicious circles. Washington DC: The World Bank, 2006.

4. Envolvem um conjunto de benefícios colocados à disposição pelo estado, empresas, famílias ou organizações, ou pela combinação destes, para reduzir múltiplos aspectos da pobreza de indivíduos ou famílias, por exemplo, desempregados de longa duração, mães sem cônjuge, idosos, crianças e jovens de famílias pobres, entre outros.

5. Abarca a proteção contra riscos da velhice, doença, acidente, desemprego, entre outros, de trabalhadores inseridos de forma registrada no mercado de trabalho que contribuem compulsoriamente para tal fim. A configuração do Sistema Público de Seguridade Social é representada por dois modelos: bismarckiano e beveridgeano. O Sistema que, depois da Segunda Guerra Mundial, se expande em praticamente todos os países ocidentais emite sinais de crise financeira e de desgaste político a partir dos anos 1970 devido a um conjunto de fatores, tais como aumento do valor e do número de benefícios, envelhecimento da população, desequilíbrio crescente entre o número de inativos e de contribuintes ao Sistema, mudanças nas relações trabalhistas e cristalização de uma imagem de desvio de focalização, desperdício e ineficiência do próprio Sistema.

6. Bouillon, C. P.; Tejerina, L. Do we know what works? A systematic review of impact evaluations of social programs in Latin America and the Caribbean. Working paper, Inter-American Development Bank, Sustainable Development Department, nov. 2006.

7. Bouillon, C. P.; Tejerina, L., Op. cit., 2006.

8. A Constituição Federal do Brasil de 1988 introduz e dinamiza ações de assistência social no âmbito do Sistema Público de Seguridade Social, entre as quais se destacam a universalização da saúde, da previdência rural e a ampliação da cobertura ao idoso e portador de deficiência. O Sistema, a partir dos anos 1990, não incorpora outras modalidades de programas orientados para o fortalecimento da cidadania, por exemplo, programas de renda mínima, ou assistencial, a grupos vulneráveis, não obstante as disposições da Constituição Federal. A prática da política pública passa a enfatizar Programas de Proteção Social.

9. Em geral, os programas aplicados em outros municípios atendem a uma pequena parcela da população pobre, transferem valores monetários insignificantes no impacto so- 
bre a pobreza — quando não substituídos por alimentos, gás de cozinha e outros —, além de terem descontinuidade. (Lavinas, L.; Barbosa, M. L. de. O. Combater a pobreza estimulando a frequência escolar: o estudo de caso do Programa Bolsa Escola do Recife. Dados, Rio de Janeiro, v. 43, n. 3, 2000.)

10. Criado pela Lei $n^{\circ} 10.291$ e regulamentado pelos Decretos $n^{\text {os }} 3.823 / 2001$ e 4.313/2002.

11. Instituído por meio da Lei no 110.836 , de 9 de janeiro de 2004, e posteriormente regulamentado pelo Decreto no 5.209, de 17 de setembro de 2004.

12. O Cadúnico foi criado em 2001 pelo Decreto no 3.877 com o objetivo de aumentar a eficiência do gasto social do governo federal ao integrar informações a respeito dos beneficiários dos programas federais existentes.

13. Ministério do Desenvolvimento Social e Combate à Fome. <http://www.mds.gov.br/>. Acesso em: out. 2008.

14. O Decreto $n^{\circ} 5.749$, de 11 de abril de 2006, altera o teto do PBF para R $\$ 120,00$.

15. O Peti também passa a compor o Sistema Único da Assistência Social (SUAS) e a contemplar a Política Nacional de Assistência Social ao fomentar o pacto entre estado e sociedade civil para garantir amplos direitos à criança e ao adolescente.

16. O programa considera como área urbana as capitais, regiões metropolitanas e municípios com mais de 250 mil habitantes.

17. Por meio do Fundo Nacional de Assistência Social ao Fundo Municipal/Estadual de Assistência Social, o Peti também distribui R \$20,00 por criança ou adolescente, destinados à Jornada Ampliada, desde que seus cadastros estejam identificados no Cadúnico.

18. Contudo, apesar de o impacto deste último programa ser bem avaliado por diversos estudos, ele não será contemplado neste trabalho devido à sua menor significância relativa se comparado com os domicílios beneficiários do Bolsa Família.

19. Basu, K. Child labor: cause, consequence, and cure, with remarks on international labor standards. Journal of Economic Literature, v. 37, n. 3, p. 1.083-1.119, 1999.

20. Vejam-se, entre outros: Cervini e Burger (1991); Nepo (1998); Kassouf (1999); Silveira, Amaral e Campineiro (2000).

21. Cacciamali, M. C.; Tatei, F. Trabalho infantil e o status ocupacional dos pais. Revista de Economia Política, São Paulo, v. 28, n. 2, p. 269-290, 2008.

22. Ferreira-Batista, N.; Cacciamali, M. C. Family migration, child labor and poverty intergenerational cycle in the State of São Paulo - Brazil. In: Annual European Association of Labour Economists Conference, 2007, Olso. Anais of Annual European Association of Labour Economists Conference, 2007.

23. Cacciamali, M. C.; Batista, N. N. F.; Tatei, F. Padrões familiares de utilização de trabalho infantil e de frequência escolar. 2007. (mimeo).

24. Psacharopoulos e Arriagada (1989); Neri e Thomas (2000); Schwartzman (2001); Parikh E Sadoulet (2005).

25. Bouillon, C. P.; Tejerina, L. Op. cit., 2006. 
26. A estimação é realizada por meio da equação: (Y1-Y0)-(Yc1-Yc0), onde $Y$ é a variável objeto, o sobrescrito $c$ corresponde ao grupo de controle e os subscritos 1 e 2 equivalem aos períodos respectivos. Os estudos, entretanto, podem apresentar metodologias distintas quanto à escolha do grupo de controle, dependendo da natureza da pesquisa e dos dados disponíveis: emparelhamento baseado no escore de propensão (propensity matching score); variáveis instrumentais (instrumental variables); casualização (randomization); ou planejamento experimental (experimental design).

27. Handa, S.; Davis, B. The experience of conditional cash transfers in Latin America and the Caribbean. Development Policy Review, Overseas Development Institute, v. 24, n. 5, p. 513-536, set. 2006.

28. Contudo, ressaltam que, em países de baixa renda, não é possível afirmar que esses programas sejam a solução ideal ou sustentável para se elevar o capital humano e reduzir a pobreza a longo prazo, na medida em que investimentos adicionais em educação e serviços de saúde de qualidade são necessários.

29. O Superémonos é um programa que oferece mensalmente cupom de alimentação no valor de 10.000,00 colones (aproximadamente US\$30,00), pagos durante 10 meses às famílias pobres, sob a condição de que todas as crianças no domicílio, com idade entre 6 e 18 anos, frequentem a escola. Duryea, S.; Morrison, A. The effect of conditional transfers on school performance and child labor: evidence from an ex-post impact evaluation in Costa Rica. Working Paper, Washington: Inter-American Development Bank, n. 505, 2004.

30. Jovens com idade entre 13 e 16 anos.

31. Os autores citam as atividades extraclasses do Peti e as visitas de agentes comunitários, intervenções nutricionais e seminários de saúde do Progresa.

32. Soares, F. V. Conditional cash transfers: a vaccine against poverty and inequality? International Poverty Centre, out. 2004. (One Page)

33. Schwartzman, S. Education-oriented social programs in Brazil: the impact of Bolsa Escola. Global Conference on Education Research in Developing Countries (Research for Results on Education), Global Development Network. Prague: IETS - Instituto de Estudos do Trabalho e Sociedade. 2005.

34. Segundo Schwartzman, atender às crianças entre 5 e 6 anos e entre 14 e 17 anos seria mais importante. O primeiro grupo não é atendido pelo sistema escolar, pois o ensino pré-escolar não é universal; para o segundo grupo, renda adicional seria importante em virtude da elevada evasão da escola nessa coorte etária.

35. Cardoso, E.; Souza, A. P. The impact of cash transfers on child labor and school attendance in Brazil. Working Papers. Department of Economics, Vanderbilt University, n. 407, 2004.

36. Ferro, A. R.; Kassouf, A. L. Avaliação do impacto dos programas de Bolsa Escola sobre o trabalho infantil no Brasil. Pesquisa e Planejamento Econômico, v. 35, p. 417, dez. 2005.

37. A amostra de 15.240 domicílios - dos quais 4.435 são beneficiários do PBF (grupo de tratamento), 4.941 nunca receberam algum tipo de benefício (grupo de comparação) e 
os demais são beneficiários de outros programas - é representativa para três grandes regiões do país (Nordeste; Norte e Centro-Oeste; Sudeste e Sul). As informações foram coletadas no período de 24.10.2005 a 5.12.2005, em 269 municípios de 24 estados. Veja-se em Cedeplar. Primeiros resultados da análise da linha de base da pesquisa de avaliação de impacto do Programa Bolsa Família. Ministério do Desenvolvimento Social e Combate a Fome, maio 2007.

38. Entretanto, ao utilizar os dados da AIBF, Andrade, Chein e Ribas (2007) verificam que os programas de transferência de renda no Brasil não apresentam efeitos significativos sobre o status nutricional das crianças com idade entre 6 e 60 meses, seja para o país como um todo, seja para os recortes regionais. Para tanto, os autores estimam o efeito médio do programa sobre os indicadores antropométricos de altura e IMC por idade, a partir do método de propensity score matching para as famílias do grupo de tratamento e comparação.

39. Soares, F. V.; Soares, S.; Medeiros, M.; Osório, R. G. Programas de transferência de renda no Brasil: impactos sobre a desigualdade. Texto para Discussão. Brasília: IPEA, n. 1.228, out. 2006. Esclarecemos que a informação é obtida a partir da desagregação da variável juros de caderneta de poupança e de outras aplicações, dividendos e outros rendimentos que recebia normalmente no mês de referência. A partir das respostas de os domicílios serem beneficiários ou não de programas sociais, os autores sugerem que essa variável seja separada em três: renda de juros, renda do BPC-LOAS e renda de outras transferências do governo. Essa divisão é selecionada em virtude do valor fixo pago aos beneficiários do BPC-LOAS de um salário mínimo, ou R\$260,00 em 2004, o que facilita a sua decomposição. Assumimos, além disso, que os valores recebidos de outros programas de transferência de renda não ultrapassam a soma de R \$260,00. Com essas informações, é possível realizar uma desagregação relativamente confiável da variável renda fornecida pela PNAD, pois qualquer rendimento extra, que não se encaixe nas duas categorias anteriores, é atribuído à variável renda de juros.

40. Veja-se, por exemplo, Cacciamali, M. C.; Batista, N. F.; Tatei, F. Op. cit., 2007.

41. Para mais detalhes sobre o probit bivariado, ver Weeks, M. e Orme, C. The statistical relationship between bivariate and multinomial choice models. Cambridge Working Paper in Economics. Department of Applied Economics, University of Cambridge, n. 99-12, 1999.

42. Definições das variáveis encontram-se no Apêndice 1 .

43. Os resultados completos das estimações podem ser conferidos no Apêndice 2.

44. Freije, S.; Lopez, C. L. Child labor, school attendance, and poverty in Mexico and Venezuela. El Colegio de Mexico, Centro de Estudios Económicos, 2001. (mimeo)

45. Já quando a variável é contínua, o efeito marginal mede em quanto muda a probabilidade quando há um aumento de uma unidade dessa característica, por exemplo, um ano a mais de estudo.

46. Os resultados positivos de programas de transferëncia de renda com condicionalidades na América Latina são avaliados, entre outros, por Bouillon e Tejerina (2006). 


\section{REFERÊNCIAS BIBLIOGRÁFICAS}

ANDRADE, M. V.; CHEIN, F.; RIBAS, R. P. Políticas de transferência de renda e condição nutricional de crianças: uma avaliação do Bolsa Família. Texto para Discussão, Belo Horizonte: Cedeplar, n. 32, 2007.

BASU, K. Child labor: cause, consequence, and cure, with remarks on international labor standards. Journal of Economic Literature, v. 37, n. 3, p. 1.083-1.119, 1999.

BOUILLON, C. P.; TEJERINA, L. Do we know what works? A systematic review of impact evaluations of social programs in Latin America and the Caribbean. Working Paper, Inter-American Development Bank, Sustainable Development Department, nov. 2006.

BRASIL. MINISTÉRIO DO DESENVOLVIMENTO SOCIAL E COMBATE À FOME. <http://www. mds.gov.br/>. Acesso em out. 2008.

CACCIAMALI, M. C.; TATEI, F. Trabalho infantil e o status ocupacional dos pais. Revista de Economia Política, São Paulo, v. 28, n. 2, p. 269-290, 2008.

; BATISTA, N. N. F. Padrões familiares de utilização de trabalho infantil e de frequência escolar. [S.1.; s.n.], 2007. (mimeo.)

CARDOSO, E.; SOUZA, A. P. The impact of cash transfers on child labor and school attendance in Brazil. Working Papers, Department of Economics, Vanderbilt University, n. 407, 2004.

CEDEPLAR. Primeiros resultados da análise da linha de base da pesquisa de avaliação de impacto do Programa Bolsa Família. Ministério do Desenvolvimento Social e Combate a Fome, maio, 2007.

CERVINI, R.; BURGER, F. O menino trabalhador no Brasil. In: FAUSTO, A.; CERVINI, R. (Orgs.). O trabalho e a rua: crianças e adolescentes no Brasil urbano dos anos 80. São Paulo: Cortez, 1991.p. 17-46.

CHAMBERS, R. What is poverty? Who asks? Who answers? In: Poverty in Focus. What is Poverty? Concepts and Measures. Brasília: IPC, dez. 2006.

DURYEA, S.; MORRISON, A. The effect of conditional transfers on school performance and child labor: evidence from an ex-post impact evaluation in Costa Rica. Working Paper, Washington: Inter-American Development Bank, n. 505, 2004.

FERREIRA-BATISTA, N.; CACCIAMALI, M. C. Family migration, child labor and poverty intergenerational cycle in the State of São Paulo - Brazil. In: ANNUAL EUROPEAN ASSOCIATION OF LABOUR ECONOMISTS CONFERENCE, 2007, Olso. Anais of Annual European Association of Labour Economists Conference, 2007.

FERRO, A. R.; KASSOUF, A. L. Avaliação do impacto dos programas de Bolsa Escola sobre o trabalho infantil no Brasil. Pesquisa e Planejamento Econômico, v. 35, p. 417, dez. 2005.

FREIJE, S.; LOPEZ, C. L. Child labor, School Attendance, and Poverty in México and Venezuela. [S. 1.]: El Colegio de Mexico, Centro de Estudios Económicos, 2001. (mimeo.)

HANDA, S.; DAVIS, B. The experience of conditional cash transfers in Latin America and the Caribbean. Development Policy Review: [S. 1.]: Overseas Development Institute, v. 24, n. 5, p. 513-536, set. 2006. 
IBGE, PESQUISA NACIONAL POR AMOSTRA DE DOMICÍLIOS, micro dados, 2004. Elaboração própria.

KASSOUF, A. L. Trabalho infantil no Brasil. Tese de Livre Docência apresentada na Escola Superior de Agricultura Luiz de Queiroz da Universidade de São Paulo. Piracicaba: 111 p., 1999.

LAVINAS, L.; BARBOSA, M. L. de O. Combater a pobreza estimulando a frequência escolar: o estudo de caso do Programa Bolsa-Escola do Recife. Dados, Rio de Janeiro, v. 43, n. 3, 2000.

NERI, M. C.; THOMAS, M. R. Household responses to labor-market shocks in Brazil 19821999. ENCONTRO NACIONAL DE ECONOMIA, 28, Anais. São Paulo: Anpec, 2000.

NÚCLEO DE ESTUDOS DE POPULAÇÃO - NEPO/UNICAMP. Trabalho infantil no Brasil: o mercado, a família e a criança. Campinas: Nepo/Unicamp, 1998, v. 1 e 2.

PARIKH, A.; SADOULET E. The effect of parents' occupation on child labor and school attendance in Brazil. UC Berkeley Manuscript, 2005.

PERRY, G. E.; ARIAS, O. S.; LÓPEZ, J. H.; MALONEY, W. F.; SERVÉN, L. Poverty Reduction and Growth: Virtuous and Vicious Circles. Washington DC: The World Bank, 2006.

PSACHAROPOULOS, G.; ARRIAGADA, A. M. The determinants of early age human capital formation: evidence from Brazil. Economic Development and Cultural Change, v. 37, n. 4, p. 683-708, 1989.

SCHWARTZMAN, S. Trabalho infantil no Brasil. Brasília: OIT, 2001.

Education-oriented social programs in Brazil: the impact of Bolsa Escola. Artigo submetido na Global Conference on Education Research in Developing Countries (Research for Results on Education), Global Development Network. Prague: IETS - Instituto de Estudos do Trabalho e Sociedade, 2005.

SILVEIRA, C.; AMARAL, C.; CAMPINEIRO, D. Trabalho Infantil: examinando o problema, avaliando estratégias de erradicação. [S. 1.]: Núcleo de Assessoria Planejamento e Pesquisa NAPP / Fundo das Nações Unidas - Unicef: nov. 2000. 46 p.

SOARES, F. V. Conditional cash transfers: a vaccine against poverty and inequality? International Poverty Centre, out. 2004. (One Page)

; SOARES, S.; MEDEIROS, M.; OSÓRIO, R. G. Programas de transferência de renda no Brasil: impactos sobre a desigualdade. Texto para Discussão, Brasília: Ipea, n. 1.228, out. de 2006.

WEEKS, M.; ORME, C. The statistical relationship between bivariate and multinomial choice models. Cambridge Working Paper in Economics, Department of Applied Economics, University of Cambridge, n. 9.912, 1999. 